\title{
Reliability of mechanical ventilation during continuous chest compressions: a crossover study of transport ventilators in a human cadaver model of CPR
}

Simon Orlob ${ }^{1,2^{*}}$ (D) Johannes Wittig ${ }^{3}$, Christoph Hobisch ${ }^{4}$, Daniel Auinger ${ }^{4}$, Gabriel Honnef ${ }^{4}$, Tobias Fellinger $^{5}$, Robin Ristl ${ }^{5}$, Otmar Schindler ${ }^{6}$, Philipp Metnitz ${ }^{4}$, Georg Feigl ${ }^{7,8}$ and Gerhard Prause ${ }^{4}$

\begin{abstract}
Background: Previous studies have stated that hyperventilation often occurs in cardiopulmonary resuscitation (CPR) mainly due to excessive ventilation frequencies, especially when a manual valve bag is used. Transport ventilators may provide mandatory ventilation with predetermined tidal volumes and without the risk of hyperventilation. Nonetheless, interactions between chest compressions and ventilations are likely to occur. We investigated whether transport ventilators can provide adequate alveolar ventilation during continuous chest compression in adult CPR.
\end{abstract}

Methods: A three-period crossover study with three common transport ventilators in a cadaver model of CPR was carried out. The three ventilators 'MEDUMAT Standard', 'Oxylog 3000 plus', and 'Monnal T60' represent three different interventions, providing volume-controlled continuous mandatory ventilation (VC-CMV) via an endotracheal tube with a tidal volume of $6 \mathrm{~mL} / \mathrm{kg}$ predicted body weight. Proximal airflow was measured, and the net tidal volume was derived for each respiratory cycle. The deviation from the predetermined tidal volume was calculated and analysed. Several mixed linear models were calculated with the cadaver as a random factor and ventilator, height, sex, crossover period and incremental number of each ventilation within the period as covariates to evaluate differences between ventilators.

Results: Overall median deviation of net tidal volume from predetermined tidal volume was $-21.2 \%$ (IQR: 19.6, range: [-87.9\%; $25.8 \%]$ ) corresponding to a tidal volume of $4.75 \mathrm{~mL} / \mathrm{kg}$ predicted body weight (IQR: 1.2, range: $[0.7 ; 7.6])$. In a mixed linear model, the ventilator model, the crossover period, and the cadaver's height were significant factors for decreased tidal volume. The estimated effects of tidal volume deviation for each ventilator were - $14.5 \%$ [95 \%-Cl: $-22.5 ;-6.5](p=0.0004)$ for 'Monnal T60', $-30.6 \%$ [95\%-Cl: $-38.6 ;-22.6](p<0.0001)$ for 'Oxylog 3000 plus' and $-31.0 \%$ [95\%-Cl: $-38.9 ;-23.0](p<0.0001)$ for 'MEDUMAT Standard'.

\footnotetext{
* Correspondence: simon.orlob@medunigraz.at

'Division of Anaesthesiology for Cardiovascular Surgery and Intensive Care

Medicine, Department of Anaesthesiology and Intensive Care Medicine,

Medical University of Graz, Auenbruggerplatz 29, 8036 Graz, Austria

${ }^{2}$ Institute for Emergency Medicine, University Hospital Schleswig-Holstein,

Campus Kiel, Arnold-Heller-Straße 3, 24105 Kiel, Germany

Full list of author information is available at the end of the article
}

(C) The Author(s). 2021 Open Access This article is licensed under a Creative Commons Attribution 4.0 International License, which permits use, sharing, adaptation, distribution and reproduction in any medium or format, as long as you give appropriate credit to the original author(s) and the source, provide a link to the Creative Commons licence, and indicate if changes were made. The images or other third party material in this article are included in the article's Creative Commons licence, unless indicated otherwise in a credit line to the material. If material is not included in the article's Creative Commons licence and your intended use is not permitted by statutory regulation or exceeds the permitted use, you will need to obtain permission directly from the copyright holder. To view a copy of this licence, visit http://creativecommons.org/licenses/by/4.0/ The Creative Commons Public Domain Dedication waiver (http://creativecommons.org/publicdomain/zero/1.0/) applies to the data made available in this article, unless otherwise stated in a credit line to the data. 
Conclusions: All investigated transport ventilators were able to provide alveolar ventilation even though chest compressions considerably decreased tidal volumes. Our results support the concept of using ventilators to avoid excessive ventilatory rates in CPR. This experimental study suggests that healthcare professionals should carefully monitor actual tidal volumes to recognise the occurrence of hypoventilation during continuous chest compressions.

Keywords: Cardiac arrest, Artificial respiration, Ventilators, mechanical, Cardiopulmonary resuscitation, Tidal volume, Reversed airflow, Out-of-hospital cardiac arrest

\section{Background}

Sudden cardiac arrest is the third leading cause of death in Europe [1]. Out-of-hospital cardiac arrest (OHCA) has an annual incidence of approximately 89 per 100,000 inhabitants, resulting in more than 400,000 resuscitation attempts by emergency medical services every year in Europe and an overall survival rate of roughly $10 \%[2,3]$. OHCA itself is a clinical condition that can be caused by several aetiologies. The predominant cause is of cardiac origin with underlying coronary disease. Cessation of organised cardiac contractions immediately leads to collapse of circulation with global ischemia, hypoxia, and global cell death.

To restore spontaneous circulation, cardiopulmonary resuscitation (CPR) strives to provide minimal perfusion with subsequent oxygen delivery to cells, predominantly of the heart and brain. Therefore, chest compressions and artificial ventilation have been a bundle of care in modern cardiac arrest treatment [4].

In recent years the role of ventilation has been comprehensively discussed $[5,6]$. A major caveat in this debate has been the risk of hyperventilation in CPR [7]. As such, previous studies have posed that hyperventilation occurs commonly in CPR, mainly due to excessive ventilation frequencies, especially when a manual valve bag is used [8]. Nevertheless, apart from ventilation frequencies, actual tidal volumes $(\mathrm{Vt})$ and minute volumes have been measured rarely in clinical CPR [8-11]. Ventilation during CPR can be synchronised with a compressionventilation ratio of $30: 2$, or asynchronous with ventilations during continuous chest compressions [12]. While the synchronous ventilation strategy limits excessive manual ventilation frequencies, asynchronous manual ventilation does not. Still, continuous chest compressions may provide increased hemodynamic benefits regarding coronary perfusion pressure and limit no-flow time $[13,14]$. Therefore, continuous chest compressions are recommended by international guidelines once the airway is secured [15].

Nevertheless, chest compressions are a counteracting force to positive pressure ventilation and may limit inspiratory volumes [16]. The risk of hypoventilation in CPR has been recently illustrated by Duchatelet et al. [11]. According to their study, chest compressions can impair tidal volumes, resulting in dead space ventilation without sufficient gas exchange.

Usage of mechanical ventilation in CPR might be a valid strategy to limit the respiratory rate and prevent tachy-ventilation during continuous chest compressions [6]. Whether common portable ventilators can provide relevant alveolar ventilation during continuous chest compressions is unknown. We sought to investigate the effect of continuous chest compressions on delivery of $\mathrm{Vt}$, using transport ventilators in adults.

\section{Methods}

A three-period crossover study with three common transport ventilators in a cadaver model of CPR was conducted. The three ventilators 'MEDUMAT Stand$\operatorname{ard}^{2}$ ' (WEINMANN Emergency Medical Technology GmbH + Co. KG, Hamburg, Germany), 'Oxylog 3000 plus' (Drägerwerk AG \& Co. KGaA, Lübeck, Germany) and 'Monnal T60' (Air Liquide Medical Systems, Antony Cedex, France) represent three different interventions providing volume-controlled continuous mandatory ventilation (VC-CMV) under continuous automated chest compressions. The latter of the three ventilators was a turbine-driven ventilator. Preparation, measurements and interventions have been conducted following an exact study protocol [see flowchart, Additional file 1].

In 1992, Walter Thiel (Graz, Austria) developed an embalming process for human cadavers preserving their natural mechanical properties, known as Thiel's method $[17,18]$. Using this method, fixation is carried out over nine months by submersion of cadavers in basins of an embalming solution. Due to the close to in-vivo texture of the tissue, these cadavers are used in surgical training. More recently, they have also been used to study respiratory mechanics in models of resuscitation $[19,20]$.

All bodies were donated to the Chair of Macroscopic and Clinical Anatomy of the Medical University of Graz, under the strict rules of the anatomical donation program according to the Styrian burial law for scientific purposes. Hence, no additional approval by the local ethical board was required. For the present study, cadavers were randomly selected from the conservation basins and stored at ambient room temperature of $23^{\circ} \mathrm{C}$. 
Cadavers were intubated orally by direct laryngoscopy. Tube positioning was verified by bronchoscopy ('aScope $^{\text {tm }} 4$ Broncho Large', Ambu ${ }^{\text {rm }}$, Ballerup, Denmark). Intrapulmonary fluid collections were suctioned through the bronchoscope's working channel; the residue of the embalming process was removed by lavage.

A differential pressure sensor ('DLVR-L60D', All Sensors Corporation, Morgan Hill, California) was installed to the sideport of a heat and moisture exchange filter connected to the endotracheal tube. The sensor was zeroed to the atmospheric pressure. A mass flow meter ('SFM3000', Sensirion AG, Staefa, Switzerland) was placed distal to the filter, in line with the artificial airway.

Each sensor was connected to an individual small single-board computer ('Raspberry Pi 3 B+', Raspberry Pi Foundation, Cambridge, United Kingdom), recording raw signals. The sample rate of the flow meter was 200 and $500 \mathrm{~Hz}$ for the differential pressure sensor.

\section{Ventilatory strategy}

The height of the cadaver was measured, and predicted body weight (PBW) was calculated using an adjusted Broca's formula [21]. Ventilatory settings were chosen in accordance with the applicable guidelines [22, 23]. Throughout the experiment, volume-controlled ventilation was used. The target tidal volume was calculated as $6 \mathrm{~mL} / \mathrm{kg}$ PBW. Tidal volumes were set to the closest possible values of the respective ventilator $\left(\mathrm{Vt}_{\mathrm{set}}\right)$. For sequences of chest compressions, a ventilatory frequency of $10 / \mathrm{min}$, no positive end-expiratory pressure (PEEP), a pressure limit $\left(\mathrm{P}_{\max }\right)$ of $60 \mathrm{cmH}_{2} \mathrm{O}$ with the shortest possible inspiratory period was used - being an inspiratory-expiratory-ratio of 1:5 for 'Monnal T60' and 'Oxylog 3000 plus', and 1:4 for 'MEDUMAT Standard'. The inspiratory period was set to the recommended inflation duration of $1 \mathrm{~s}$.

\section{Chest compressions}

Standardised chest compressions were performed using an automated chest compression piston device ('Corpuls CPR', GS Elektromedizinische Geräte G. Stemple $\mathrm{GmbH}$, Kaufering, Germany). To avoid synchronisation of the chest compression phase and respiratory cycle, as given by a frequency of $100 / \mathrm{min}$ and $10 / \mathrm{min}$, a chest compression frequency of $103 / \mathrm{min}$ and a compression depth of $5 \mathrm{~cm}$ was used.

\section{Study protocol}

Respiratory mechanics were monitored by repeated pressure-volume curves ( $\mathrm{P} / \mathrm{V}$ loop) with an intensive care ventilator ('HAMILTON-C6', Hamilton Medical Inc., Bonaduz, Switzerland). Static compliance $\left(C_{\text {stat }}\right)$ was derived as the maximum slope of the inspiratory leg.
Pneumothorax was ruled out by sonography after every two-minute cycle of chest compressions.

The initial aeration of the lung was carried out with the previously mentioned intensive care ventilator. Two quasi-static inflation manoeuvres were performed using a top pressure of 25 and $30 \mathrm{cmH}_{2} \mathrm{O}$. This was followed by a 15 -minute sequence of ventilation (VC-CMV: Vt 6 $\mathrm{mL} / \mathrm{kg}$ PBW, f 12/min; PEEP $5 \mathrm{cmH}_{2} \mathrm{O}$, I:E 1:2, $\mathrm{P}_{\max } 40$ $\mathrm{cmH}_{2} \mathrm{O}$ ) [s. blue segment of flowchart, Additional file 1].

Lung and thoracic properties were assessed utilising three separate sequences, lasting two minutes each. During the first sequence only ventilation was provided, followed by chest compressions only, concluding with a combined sequence of chest compressions and ventilation [s. green segment of flowchart, Additional file 1].

The three transport ventilators were tested in a threeperiod crossover design. Each period consisted of two, two-minute-long segments of simulated CPR [s. yellow segment of flowchart, Additional file 1]. The possible permutations of ventilator orders were calculated in advance and randomly assigned to the individual cadaver using sealed envelopes.

In this publication, the results of the three-period crossover study are presented.

\section{Data processing \& statistical analysis}

Raw signals were processed with 'MATLAB' (MathWorks, Natick, Massachusetts, United States). Tidal volumes were derived from the flow signal for every single respiratory cycle. Cumulative inspiratory volume was calculated as the volume of the total inward-directed airflow over the whole respiratory cycle $\left(\mathrm{V}_{\text {insp-sum }}\right)$; thus, air movements due to chest compressions are also included. Inspiratory tidal volume was calculated as maximal inspiratory volume $\left(\mathrm{Vt}_{\text {insp }}\right)$, therefore as the volume of net air inflow (s. Figure 1). Correspondingly, the same volumes were calculated for expiratory flow. Reverse airflow was calculated as the volume of opposite directed airflow to the respiratory phase - hence outwarddirected airflow during the inspiratory phase and inward-directed airflow during the expiratory phase.

Missed inspiratory tidal volume $\left(\mathrm{Vt}_{\text {insp-missed }}\right)$ was calculated as the deviation in percentage of inspiratory net tidal volume from $\mathrm{Vt}_{\text {set. }}$. Peak flow was directly derived as inspiratory maxima for each respiratory cycle. Peak airway pressure was derived as maxima during the decompression phase for each respiratory cycle.

Two investigators (J.W. and S.O.) reviewed each ventilation separately and excluded ventilations without continuous chest compressions to the full depth of $5 \mathrm{~cm}$ in the inspiratory phase from further analysis.

Standard statistic software was used ('IBM SPSS Statistics for Macintosh', Version 26.0, IBM Corp., Armonk, New York, United States; 'SAS 9.4', SAS Institute, Cary, 


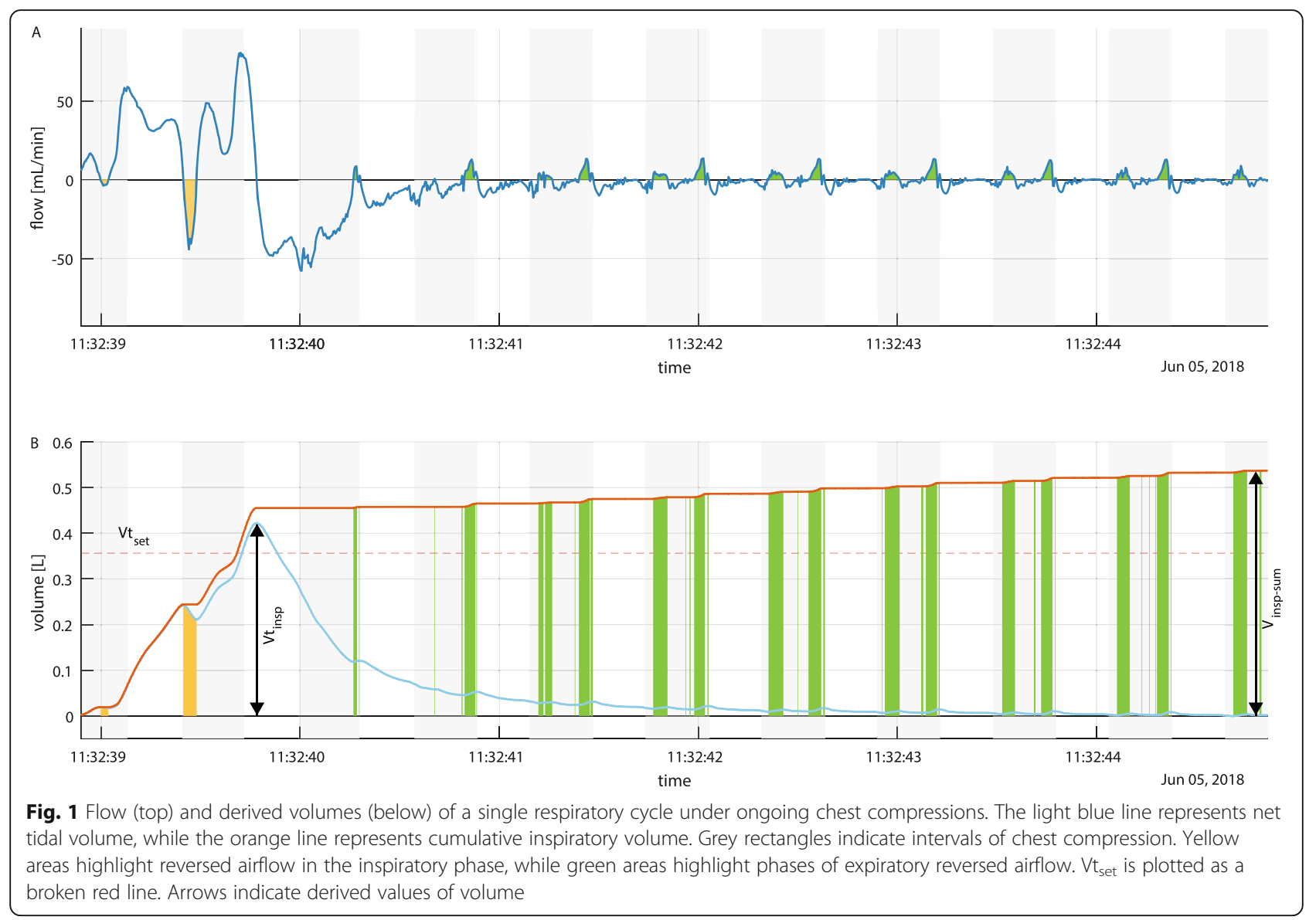

North Carolina, United States; 'R 3.6.1'., R Development Core Team) for analysis. Parametric and non-parametric tests were conducted as indicated. Linear mixed models were calculated for $\mathrm{Vt}_{\text {insp-missed }}$, peak flow and peak airway pressure, each with the cadaver as the random factor and ventilator, height, sex, crossover period and incremental number of each ventilation within the period as covariates. The model specification allowed for different variances for each device. All data are reported as mean \pm SD or median (IQR, [Minimum; Maximum]), as appropriate. Estimates are presented with their $95 \%$ confidence interval.

\section{Results}

\section{Model characteristics}

Six cadavers (three female, three male) were included in the study. Characteristics of cadavers and derived values are shown in Table 1. All measurements are available as raw data in a repository [24]. An executable plotting tool is available from another repository to review these ventilatory tracings [25].

Median $\mathrm{C}_{\text {stat }}$ was $30.1(11.9,[25 ; 51.5]) \mathrm{mL} / \mathrm{mbar}$ before chest compressions were started and increased with the first set of chest compressions up to 38.8 (19.8, $[32.5 ; 70.3]) \mathrm{mL} / \mathrm{mbar}(p=0.03)$. Further increase of static compliance was more subtle over the course of the experiment (2nd P/V loop: $43.1(14.6,[31.3 ; 67.1]) \mathrm{mL} /$ mbar, 3rd P/V loop: 48.5 (21.9, [34.8; 76.3]) mL/mbar, final P/V loop: 49.7 (22.2, [34.7; 70.8]) $\mathrm{mL} / \mathrm{mbar}(p=$ 0.042) [s. Additional file 2].

\section{Tidal volumes}

Within the 36 segments of simulated CPR, 757 single ventilations were recorded, of which 715 were valid for further analysis.

Inspiratory and expiratory tidal volumes differed in median by + $1.14(8.68,[-24.5 ; 35.4]) \mathrm{mL}$.

Overall, the delivered median $\mathrm{Vt}_{\text {insp }}$ was 274.8 (68.3 [47; 463.6]) $\mathrm{mL}$. Normalized for body weight a median $\mathrm{Vt}_{\text {insp }}$ of $4.75(1.2[0.7 ; 7.6]) \mathrm{mL} / \mathrm{kg} \mathrm{PBW}$.

$\mathrm{Vt}_{\text {insp-missed }}$ - meaning the percentage deviation of $\mathrm{Vt}_{\text {insp }}$ from the predetermined tidal volume $\left(\mathrm{Vt}_{\text {set }}\right)$ - was - 21.2 (19.6, [- 87.9; 25.8]) \%. For each ventilator Vt $t_{\text {insp }}$ -missed was in median $-8.3(20.5,[-87.9 ; 25.8) \%$ for 'Monnal T60', - 22.7 (22.1, [-70; - 12.3]) \% for 'Oxylog 
Table 1 Characteristics and calculated ventilatory settings of individual cadavers

\begin{tabular}{|c|c|c|c|c|c|c|c|c|c|c|}
\hline \multirow[t]{2}{*}{ ID } & \multirow[t]{2}{*}{ sex } & \multirow{2}{*}{$\begin{array}{l}\text { age } \\
\text { [years] }\end{array}$} & \multirow{2}{*}{$\begin{array}{l}\text { height } \\
{[\mathrm{cm}]}\end{array}$} & \multirow{2}{*}{$\begin{array}{l}\text { PBW } \\
\text { (calculated) } \\
\text { [kg] }\end{array}$} & \multirow{2}{*}{$\begin{array}{l}\mathrm{C}_{\text {stat }} \\
\text { initial } \\
{[\mathrm{mL} /} \\
\text { mbar }]\end{array}$} & \multirow{2}{*}{$\begin{array}{l}\mathrm{Vt}_{\text {opt }} \text { (calculated } 6 \\
\mathrm{~mL} / \mathrm{kg})[\mathrm{mL}]\end{array}$} & \multicolumn{3}{|c|}{$\mathrm{Vt}_{\text {set }}[\mathrm{mL}]$} & \multirow[t]{2}{*}{ Pneumothorax } \\
\hline & & & & & & & $\begin{array}{l}\text { ‘Monnal } \\
\text { T60' }\end{array}$ & $\begin{array}{l}\text { ‘Oxylog } 3000 \\
\text { plus' }\end{array}$ & $\begin{array}{l}\text { 'MEDUMAT } \\
\text { Standard }{ }^{2 \prime}\end{array}$ & \\
\hline G73 & female & 89 & 166 & 59.4 & 34.6 & 356 & 360 & 360 & 350 & $\begin{array}{l}\text { left, post 2nd } \\
\text { period }\end{array}$ \\
\hline G84 & male & 81 & 171 & 67.5 & 35.2 & 405 & 410 & 410 & 400 & $\begin{array}{l}\text { right, post 2nd } \\
\text { period }\end{array}$ \\
\hline G87 & female & 90 & 172 & 64.8 & 70.3 & 389 & 390 & 390 & 400 & $\begin{array}{l}\text { left, post 2nd } \\
\text { period }\end{array}$ \\
\hline G88 & male & 74 & 168 & 64.6 & 42.5 & 388 & 390 & 390 & 400 & none \\
\hline G74 & male & 83 & 166 & 62.7 & 32.5 & 376 & 380 & 380 & 400 & none \\
\hline G83 & female & 81 & 154 & 48.6 & 48.5 & 292 & 290 & 290 & 300 & none \\
\hline
\end{tabular}

3000 plus' and -31.5 (16.6, $[-56.5 ;-14.8]) \%$ for 'MEDUMAT Standard'.

In a mixed linear model ventilator, crossover period and height were significant factors for $\mathrm{Vt}_{\text {insp-missed }}[\mathrm{s}$. Additional file 3]. The estimated population means of $\mathrm{Vt}_{\text {insp-missed }}$ for ventilator models were -14.5 [95\%-CI: $-22.5 ;-6.48] \%(p=0.0004)$ for 'Monnal T60', - 30.6 [95\%-CI: $-38.6 ;-22.6] \%(p<0.0001)$ for 'Oxylog 3000 plus' and -31 [95\%-CI: $-38.9 ;-23] \%(p<0.0001)$ for 'MEDUMAT Standard'.

Cumulative inspiratory volume $\left(\mathrm{V}_{\text {insp-sum }}\right)$ - meaning the total volume of inward-directed airflow over a single respiratory cycle - deviated from predetermined volume in median by $+20.1(29.4,[-72.9 ; 58.6]) \%$ for 'Monnal T60', - 9.1 (25.6, [- 54.8; 9.4]) \% for 'Oxylog 3000 plus' and + 0.4 (19.3, [- 36.9; 22.7]) \% for 'MEDUMAT Stand$\operatorname{ard}^{2}$ ' (s. Figure 2).

Inspirations and expirations were fragmented by chest compressions. Per respiratory cycle of reversed airflow episodes, exceeding $1 \mathrm{~mL}$ of volume, occurred in median $1(0,[0 ; 2])$ time in inspiratory phase and 7 (1, [0;9]) times in expiratory phase. Reversed airflow resulted in a median volume of 0.95 (0.96, [0.05; 2.87]) $\mathrm{mL} / \mathrm{kg} \mathrm{PBW}$ over the whole respiratory cycle, of which in median $0.05(0.1,[0 ; 0.7]) \mathrm{mL} / \mathrm{kg} \mathrm{PBW}$ occurred during inspiration and $0.87(0.79[0 ; 2.48])$ $\mathrm{mL} / \mathrm{kg}$ PBW during expiration. Maximal volume of a single episode of reversed airflow was $0.7 \mathrm{~mL} / \mathrm{kg}$ PBW, corresponding to $45.6 \mathrm{~mL}$.

\section{Flow and airway pressure}

Median peak flow was 68.5 (23.6, [ 20.7; 93]) L/min, 44.4 (11, [27.9; 57.9]) L/min, 43.5 (8.1, [31.2; 54,9]) L/min for 'Monnal T60', 'Oxylog 3000 plus' and 'MEDUMAT Standard ${ }^{2}$, respectively. In a mixed linear model, we found that the differences of estimated effects by ventilators on peak flow between 'Oxylog 3000 plus' and 'Monnal T60' as well as between 'MEDUMAT Standard' and 'Monnal T60' were significant $(p<0.001)$.
The median peak airway pressure during decompression phase was 46.6 (10.7, [30.2; 64.4]) mbar for 'Monnal T60', 55.5 (12.6, [27.9; 66]) mbar 'Oxylog 3000 plus' and 48.5 (14.4, [27; 73.3]) mbar Medumat Standard ${ }^{2}$. According to the linear mixed model, the differences between the estimated effects of ventilator models on airway pressure were significant $(p<0.001)$.

\section{Discussion}

Our main finding is that all ventilators were able to provide tidal volumes exceeding anatomical deadspace under ongoing chest compressions with volumecontrolled mandatory ventilation and a ventilatory frequency of $10 / \mathrm{min}$. Thereby, all ventilators were able to deliver tidal volumes required for alveolar ventilation and gas exchange.

However, we also found all tested ventilators to provide substantially smaller tidal volumes than preset. Interestingly, the extent to which the tidal volumes were diminished was dependent on the ventilator model. While we found the turbine-driven ventilator to perform best, both pneumatic ventilators missed the preset tidal volume by almost a third. This compares to the results of a manikin study [16] and corresponds to the suspicion of hypoventilation in our previous clinical studies of blood gases in OHCA [26, 27]. These found that contrary to the common perception of hyperventilation in CPR, hypocapnia leading to alkalosis was not observed at all. Instead, most patients were found to be hypercapnic.

Oxygenation and decarboxylation are perceived as cornerstones of resuscitation efforts. Excessive hyperventilation has been shown to have detrimental effects on haemodynamics and resuscitation outcomes in an animal study [7]. In a trial with clinically more realistic tidal volumes, those results were not reproducible [28]. It is to be noted that the tidal volumes used in our experiment were substantially smaller than those used by Aufderheide and Gazmuri [7, 28, 29]. 

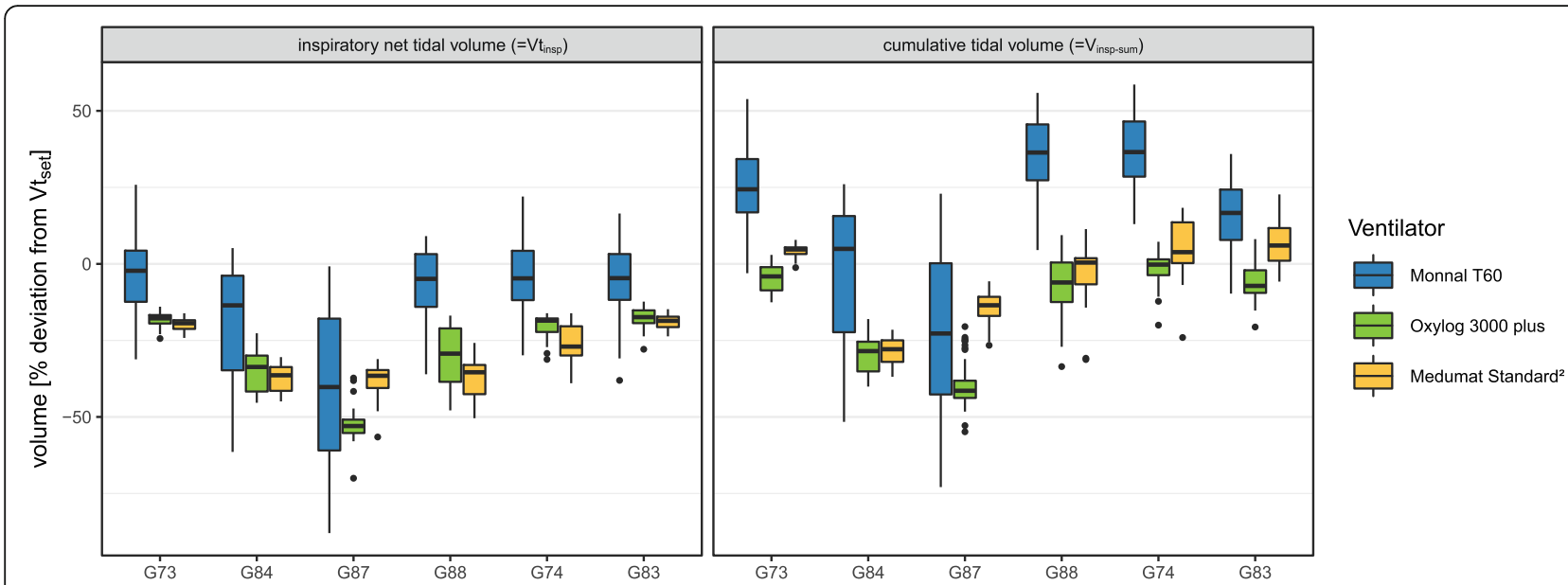

Fig. 2 Deviation of net tidal volume from $\mathrm{Vt}_{\mathrm{set}}$ for every single ventilation ( $\left.=\mathrm{Vt}_{\text {insp-missed }}\right)$ as scatter plot separated for each ventilation crossover period. Colour represents the ventilator model. Marker shape represents individual cadavers. Trend lines are plotted for each two-minute-long segment of CPR and each particular cadaver separately

We observed a periodical overshoot in net tidal volume in the turbine-driven ventilator, which indicates an internal control mechanism to compensate for diminished tidal volumes (s. Figure 3). This is a clinically relevant finding, as it implies that ventilators - although operating in the same mode - behave substantially different under ongoing chest compressions. The higher peak flow of the turbine-driven ventilator may suggest this device can deliver inspiratory flow more instantaneously during decompressions with less peak airway pressure.

We used endotracheal intubation as the airway gold standard with continuous chest compressions as recommended by the current guidelines [30]. The respiratory system was sealed, without a difference between inspiratory and expiratory tidal volumes. Clinically the focus should be on expiratory volumes, as they characterise alveolar ventilation more reliably due to possible leakage. For statistical analysis, we used the inspiratory volumes to quantify ventilation, as expiratory tidal volumes are influenced more by volatile changes of respiratory resting position due to chest compressions.

Chest compressions fragment ventilation through the occurrence of opposite directed airflow, known as reversed airflow. Compared to the observations by Duchatelet [11], we observed smaller volumes of reversed airflow and even episodes of opposite directed airflow in the expiratory phase. None of our observed reversed airflow episodes exceeded anatomical dead space. Thus, reversed airflow did not contribute to alveolar ventilation in our experiment but explains the difference between cumulative and net tidal volume. The distinction between cumulative and net tidal volumes is relevant. Total inspiratory airflow $\left(\mathrm{V}_{\text {insp-sum }}\right)$ might suggest sufficient ventilation, while alveolar ventilation could be substantially less or even insufficient. Since we did not record displayed volumes of the ventilators, we cannot report the accuracy of their internal measurements and calculations. However, our results emphasise that the internal algorithm of the ventilators to calculate tidal volumes in CPR is of importance. Furthermore, our observations suggest that ventilatory volumes in CPR need to be reported and discussed in a more differentiated manner. Due to leakage and reversed airflow several varying tidal volumes can be calculated for a single ventilation. This should be acknowledged in clinical research to grant comparability of results, but also in clinical practice as only volumes contributing to gas exchange are meaningful.

Usage of human cadavers to study airflow phenomena might be advantageous over animal models as animals have substantial differences in the airway and thoracic configuration [31]. However, cadaver models are not suitable to observe haemodynamics, gas exchange or metabolic processes during resuscitation. In our experiment, static compliance was comparable to those observed previously in Thiel-embalmed cadavers [19] and immediately after termination of CPR [32].

The embalming process enriches the corpses with fluid. This might have contributed to the effect of increasing compliance with the application of chest compressions, possibly forcing fluid out of the parenchyma. Although the observed changes of static compliance were within a clinically plausible range, this might indicate deterioration of the model over time. Breakdown of endothelial function and the fluid load of the corpse are substantial limitations of this model.

Statistically, we compensated for deterioration effects over the course of the experiment. Due to the small sample size, we could not compensate for any carry-over effects in this crossover study. We have no 

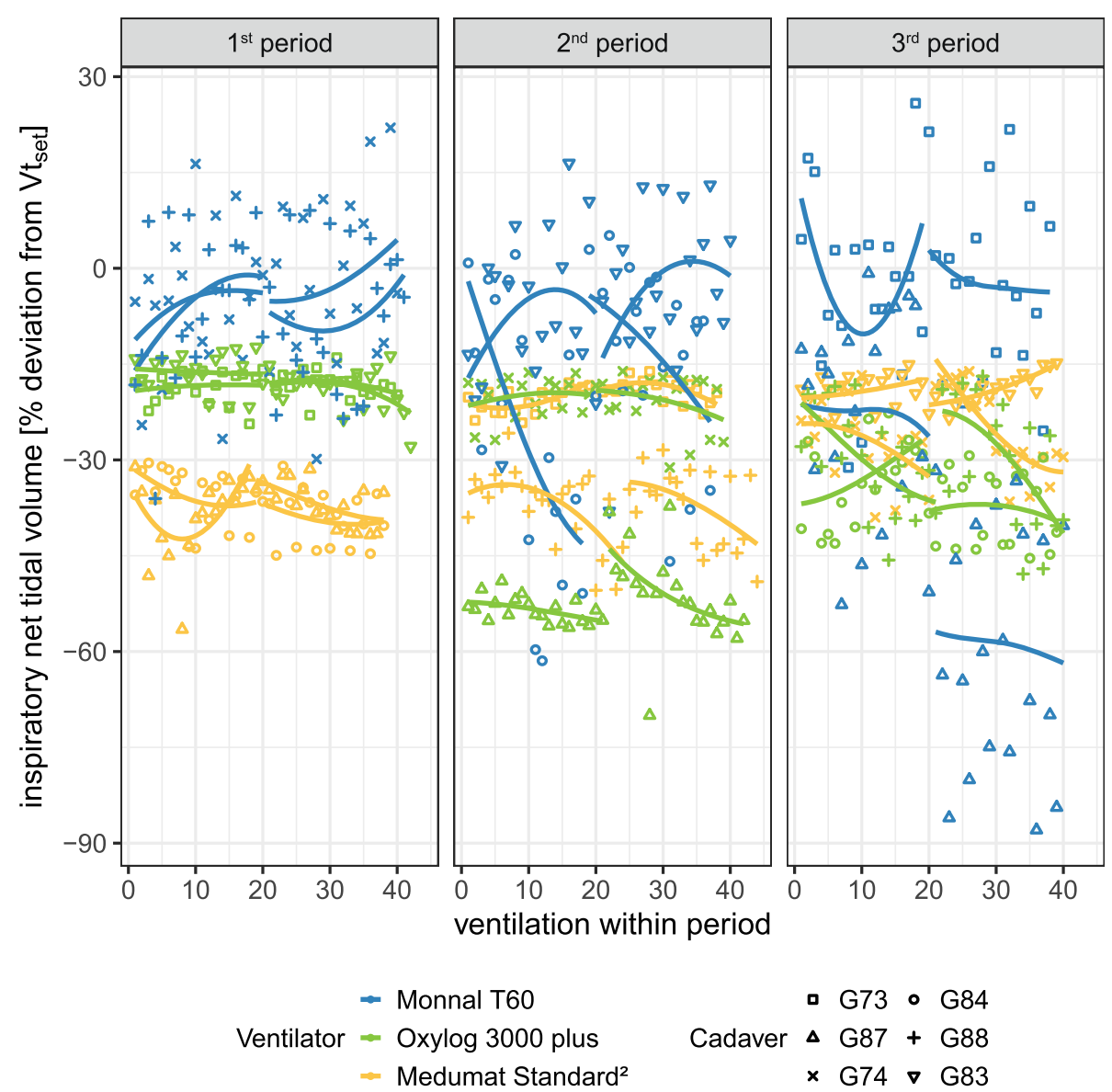

Fig. 3 Deviation of the net (left) and cumulative (right) tidal volume from $\mathrm{Vt}_{\mathrm{set}}$ as boxplot for each ventilator model grouped by individual cadavers. Colour represents the ventilator model. Note that due to standardization of the $y$-axis, $\mathrm{Vt}_{\text {insp }}$ resembles $\mathrm{Vt}_{\text {insp-missed }}$

comprehensive medical history of the body donors; therefore, pre-existing pulmonary conditions might have had an impact on cadaver-specific properties. This was considered in our statistical modelling with the cadavers as a random factor.

We used volume-controlled ventilation, as chest compressions increase airway pressure and thereby disturb pressure-controlled ventilation. This procedure is also recommended by recent guidelines [33]. Volumecontrolled mode is standard in all ventilators but is more prone to cause barotrauma. When airway pressure exceeds $P_{\max }$, the expiratory valve is opened to reduce airway pressure. In CPR, peak airway pressure occurs during the compression phase. It has to be emphasised that this is the result of an extrapulmonary pressure increase and is as such not a cause for barotrauma per se, as transpulmonary pressure is not elevated [34]. In the present paper we are reporting peak airway pressure during the relaxation phase of chest compressions.

We chose a ventilatory strategy in accordance with the previous guidelines $[22,23]$. These ventilatory settings also meet the 2021 guideline recommendations [30, 33], especially regarding the ventilatory mode, $\mathrm{P}_{\max }$, and ventilatory frequency. Even more, our approach lines up well with recently published ventilatory strategies for CPR [35, 36]. Nevertheless, we chose a conservative tidal volume of $6 \mathrm{~mL} / \mathrm{kg}$ PBW, which is at the lower spectrum of the recommended 6-7 ml/kg PBW in the 2015 guidelines [22] and $2 \mathrm{ml} / \mathrm{kg}$ PBW less than recommended in the "Six-dial Strategy" [36]. Equally conservative, we decided to not use PEEP, although this is a controversial topic [37, 38]. While our settings avoided high airway pressures due to large tidal volumes and PEEP, both may have contributed to airway closure and atelectasis.

During CPR, atelectasis is common in dorsal lung areas with cyclic recruitment [39]. The increased ventilation in ventral lung areas implies the risk for volutrauma in those areas, while atelectotrauma occurs in the dorsal regions. As per protocol, we monitored for pneumothoraces. Those found by sonography were minor, did not reduce lung compliance and resulted in no air discharge upon thoracostomy at the end of the experiment.

In CPR, a severe ventilation-perfusion mismatch is present. Yet finding optimal ventilatory strategies is still 
an unsolved problem. Capnography as a sole concentration measurement of carbon dioxide is influenced by pulmonary blood flow and cannot quantify ventilation alone [40]. As in the present study, measurement of expiratory tidal volumes should become a clinical standard, as already demanded by Ornato et al. in 1983 [9]. Recent advances in technology made this readily available for manual ventilation as well $[11,41]$. Furthermore, the nexus of capnography with tidal volumes as volumetric capnography might be a field of future developments in individualised, goal-directed CPR [42, 43].

\section{Conclusions}

Our findings support the concept of using transport ventilators to limit the ventilation rate. Nevertheless, we also observed ventilations with severely low tidal volumes. Therefore, healthcare providers should closely monitor expiratory tidal volumes when using mechanical ventilation during continuous chest compressions without relying on preset values.

Due to reversed airflow, ventilations are fragmented in CPR, with a significant portion of airflow presumably not contributing to alveolar ventilation. Therefore, tidal volumes have to be considered in a much more differentiated way under ongoing chest compressions in clinical research to grant comparability of results, but also in clinical practice as only volumes contributing to gas exchange are meaningful. Future clinical studies are needed to confirm our findings.

\section{Abbreviations}

95\%-Cl: $95 \%$ confidence interval; $\mathrm{AADCO}_{2}$ : Arterio-alveolar carbon dioxide gradient; CPR: Cardiopulmonary resuscitation; $\mathrm{C}_{\text {stat }}$ : Static compliance; IQR: Interquartile range; OHCA: Out-of-hospital cardiac arrest; PN loop: Pressure-volume loop; PBW: Predicted body weight; PEEP: Positive endexpiratory pressure; $P_{\text {max }}$ : Pressure limit; VC-CMV: Volume controlled continuous mandatory ventilation; $V_{\text {insp-sum: }}$ Cumulative inspiratory volume (volume of the total inward-directed airflow for a respiratory cycle); Vt: Tidal volume; $\mathrm{Vt}_{\mathrm{insp}}$ : Inspiratory net tidal volume; $\mathrm{Vt}_{\text {insp-missed: }}$ Missed inspiratory tidal volume (difference of $\mathrm{Vt}_{\text {insp }}$ and $\mathrm{Vt}_{\text {set }}$ ); $\mathrm{Vt}_{\text {set: }}$ : Preset tidal volume

\section{Supplementary Information}

The online version contains supplementary material available at https://doi. org/10.1186/s13049-021-00921-2.

Additional file 1. Experiment flowchart. Colour represents the phase of the experiment. Detailed ventilator and chest compression settings are given within the text balloons. Note that the yellow segment illustrates the crossover study, and the iterative workflow is only provided for the first period in detail.

Additional file 2. Repetitive pressure-volume loops over the course of the experiment for each cadaver obtained by quasi-static inflationdeflation manoeuvres. Colour represents the chronological order of PN loops.

Additional file 3. Contrasts and coefficients of the three presented mixed linear models

\section{Acknowledgements}

First and foremost, we thank all body donors for their invaluable donations to science and education.
We want to thank Jan Wnent, Theresa Berthold, Paul Zajic, Gregor Schittek, Andreas Sandner-Kiesling, Aidan Baron, and Angela Poli-Schöpfer for careful review of the manuscript. Especially we thank Otto Touzil for programming the drivers for the used sensors.

We would like to thank the Austrian Association of Emergency and Disaster Medicine (abbr.: ÖNK) and Medizinercorps Graz Alumni for making this research possible.

\section{Authors' contributions}

Conceptualisation SO, JW, GP; Methodology SO, JW, CH, DA, GH, OS, GF, GP; Software SO, CH; Formal analysis SO, TF, RR; Investigation SO, JW, CH, DA, GH, GP; Data Curation SO, JW, CH; Writing- Original Draft SO, JW, TF; Writing - Review \& Editing DA, RR, OS, PM, GF, GP; Visualization SO, JW, CH, TF; Project administration SO, GP; Resources PM, GF; Supervision PM; Funding acquisition SO. All authors read and approved the final manuscript.

\section{Funding}

This study was funded by the Austrian Association of Emergency and Disaster Medicine (abbr.: ÖNK) with the "Reinhard Malzer Award". However, the association did not interfere with any steps towards this paper. Open Access funding enabled and organized by Projekt DEAL.

\section{Availability of data and materials}

The datasets generated and analysed during the current study are available in the Data Mendeley repository, https://doi.org/10.17632/vh4tdsscns.1. An interactive visualisation tool to review the data is available from Data Mendeley repository, https://doi.org/10.17632/43h7zzp67k.3 (operating system: Windows; other requirements: MATLAB Runtime; license: CC BY 4.0).

\section{Declarations}

Ethics approval and consent to participate

All bodies were donated to the Chair of Macroscopic and Clinical Anatomy of the Medical University of Graz, under the strict rules of the anatomical donation program according to the Styrian burial law for scientific purposes. Hence, no additional approval by the local ethical board was necessary.

Consent for publication

Not applicable.

\section{Competing interests}

SO has received a grant to fund this study (s. above). GP has given a talk at a national symposium, invited by RWM Medizintechnik GmbH. All other authors have no personal conflict of interest

Medical devices and equipment used in this study were kindly lent by the following companies: CHEMOMEDICA Medizintechnik und Arzneimittel VertriebsgmbH, Löwenstein Medical Austria GmbH, Sanitas GmbH, GS Elektromedizinische Geräte G. Stemple GmbH, Dräger Austria GmbH, WEIN MANN Emergency Medical Technology, RWM Medizintechnik GmbH. No company or manufacturer had influence on the study protocol, statistical analyses, nor was involved in writing of this paper.

\section{Author details}

${ }^{1}$ Division of Anaesthesiology for Cardiovascular Surgery and Intensive Care Medicine, Department of Anaesthesiology and Intensive Care Medicine, Medical University of Graz, Auenbruggerplatz 29, 8036 Graz, Austria. ${ }^{2}$ Institute for Emergency Medicine, University Hospital Schleswig-Holstein, Campus Kiel, Arnold-Heller-Straße 3, 24105 Kiel, Germany. ${ }^{3}$ Medical University of Graz, Auenbruggerplatz 2, $8036 \mathrm{Graz}$, Austria. ${ }^{4}$ Division of General Anaesthesiology, Emergency- and Intensive Care Medicine, Department of Anaesthesiology and Intensive Care Medicine, Medical University of Graz, Auenbruggerplatz 29, 8036 Graz, Austria. ${ }^{5}$ Centre for Medical Statistics, Informatics and Intelligent Systems, Medical University of Vienna, Spitalgasse 23, 1090 Vienna, Austria. ${ }^{6}$ Department of Internal and Respiratory Medicine, Intensive Care Unit Enzenbach, State Hospital Graz II, Hörgas 30, 8112 Gratwein, Austria. ${ }^{7}$ Division of Macroscopic and Clinical Anatomy, Medical University of Graz, Harrachgasse 21, $8010 \mathrm{Graz}$, Austria. ${ }^{8}$ Institute of Morphology and Clinical Anatomy, Faculty of Health/School of Medicine, Witten/Herdecke University, Witten, Germany. 
Received: 13 April 2021 Accepted: 14 July 2021

Published online: 28 July 2021

\section{References}

1. Gräsner J-T, Herlitz J, Tjelmeland IBM, Wnent J, Masterson S, Lilja G, et al. European resuscitation council guidelines 2021: epidemiology of cardiac arrest in Europe. Resuscitation. 2021;161:61-79.

2. Gräsner J-T, Wnent J, Herlitz J, Perkins GD, Lefering R, Tjelmeland I, et al. Survival after out-of-hospital cardiac arrest in Europe - results of the EuReCa TWO study. Resuscitation. 2020;161:61-79.

3. Yan S, Gan Y, Jiang N, Wang R, Chen Y, Luo Z, et al. The global survival rate among adult out-of-hospital cardiac arrest patients who received cardiopulmonary resuscitation: a systematic review and meta-analysis. Crit Care. 2020;24:61

4. Safar P, Brown TC, Holtey WJ, Wilder RJ. Ventilation and circulation with closed-chest cardiac massage in man. JAMA. 1961;176:574.

5. Chang MP, Idris $\mathrm{AH}$. The past, present, and future of ventilation during cardiopulmonary resuscitation. Curr Opin Crit Care. 2017;23:188-92.

6. Orso D, Vetrugno L, Federici N, Borselli M, Spadaro S, Cammarota G, et al. Mechanical ventilation management during mechanical chest compressions. Respir Care. 2020;66:334-46.

7. Aufderheide TP, Sigurdsson G, Pirrallo RG, Yannopoulos D, McKnite S, von Briesen C, et al. Hyperventilation-induced hypotension during cardiopulmonary resuscitation. Circulation. 2004:109:1960-5.

8. O'Neill JF, Deakin CD. Do we hyperventilate cardiac arrest patients? Resuscitation. 2007:73:82-5

9. Ornato J, Bryson B, Donovan P, Farquharson R, Jaeger C. Measurement of ventilation during cardiopulmonary resuscitation. Crit Care Med. 1983;11:79-82

10. Dorph E, Wik L, Steen PA. Arterial blood gases with $700 \mathrm{ml}$ tidal volumes during out-of-hospital CPR. Resuscitation. 2004;61:23-7.

11. Duchatelet C, Kalmar AF, Monsieurs KG, Hachimi-Idrissi S. Chest compressions during ventilation in out-of-hospital cardiac arrest cause reversed airflow. Resuscitation. 2018:129:97-102.

12. Olasveengen TM, Caen AR de, Mancini ME, Maconochie IK, Aickin R, Atkins DL, et al. 2017 International Consensus on Cardiopulmonary Resuscitation and Emergency Cardiovascular Care Science With Treatment Recommendations Summary. Resuscitation. 2017:121:201-14.

13. Kern KB, Hilwig RW, Berg RA, Sanders AB, Ewy GA. Importance of Continuous Chest Compressions During Cardiopulmonary Resuscitation. Circulation. 2002;105:645-9.

14. Berg RA, Sanders AB, Kern KB, Hilwig RW, Heidenreich JW, Porter ME, et al. Adverse Hemodynamic Effects of Interrupting Chest Compressions for Rescue Breathing During Cardiopulmonary Resuscitation for Ventricular Fibrillation Cardiac Arrest. Circulation. 2001:104:2465-70.

15. Soar J, Nolan JP, Böttiger BW, Perkins GD, Lott C, Carli P, et al. European Resuscitation Council Guidelines for Resuscitation 2015. Resuscitation. 2015; 95:100-47.

16. Speer T, Dersch W, Kleine B, Neuhaus C, Kill C. Mechanical ventilation during resuscitation: how manual chest compressions affect a ventilator's function. Adv Ther. 2017:34:2333-44

17. Thiel W. Die Konservierung ganzer Leichen in natürlichen Farben. Ann Anat. 1992;174:185-95.

18. Thiel W. Ergänzung für die Konservierung ganzer Leichen nach W. Thiel. Ann Anat. 2002;184:267-9.

19. Charbonney E, Delisle S, Savary D, Bronchti G, Rigollot M, Drouet A, et al. A new physiological model for studying the effect of chest compression and ventilation during cardiopulmonary resuscitation: the Thiel cadaver. Resuscitation. 2018;125:135-42.

20. Duhem H, Viglino D, Bellier A, Tanguy S, Descombe V, Boucher F, et al. Cadaver models for cardiac arrest: a systematic review and perspectives. Resuscitation. 2019;143:68-76.

21. Larsen R, Ziegenfuß T, Mathes A. Einstellgrößen am Beatmungsgerät. In: Larsen R, Ziegenfuß T, Mathes A, editors. Beatmung. 6th ed. Heidelberg: Springer; 2018. p. 263-83.

22. Perkins GD, Handley AJ, Koster RW, Castrén M, Smyth MA, Olasveengen T, et al. European Resuscitation Council Guidelines for Resuscitation 2015 Sec 2. Adult basic life support and automated external defibrillation. Resuscitation. 2015:95:81-99.

23. Soar J, Nolan JP, Böttiger BW, Perkins GD, Lott C, Carli P, et al. European Resuscitation Council Guidelines for Resuscitation 2015 Sec. 3. Adult advanced life support. Resuscitation. 2015;95:100-47.
24. Orlob S, Hobisch C, Wittig J, Auinger D, Honnef G, Touzil O, et al. Data for: Do emergency ventilators deliver preset tidal volumes? - Mechanical ventilation in a human cadaver model of asynchronous cardiopulmonary resuscitation. Data Mendeley. 2020:V1. https://doi.org/10.17632/vh4tdsscns.1

25. Orlob S, Hobisch C. ThielViewer - an interactive visualization tool for: Do emergency ventilators deliver preset tidal volumes? - Mechanical ventilation in a human cadaver model of asynchronous cardiopulmonary resuscitation. Mendeley Data. 2021;V3. https://doi.org/10.17632/43h7zzp67k.3.

26. Spindelboeck W, Gemes G, Strasser C, Toescher K, Kores B, Metnitz P, et al. Arterial blood gases during and their dynamic changes after cardiopulmonary resuscitation: A prospective clinical study. Resuscitation. 2016;106:24-9.

27. Prause G, Zoidl P, Zajic P. Hyperventilation is uncommon during cardiopulmonary resuscitation: a preliminary observational study. Resuscitation. 2021;162:257-8

28. Gazmuri RJ, Ayoub IM, Radhakrishnan J, Motl J, Upadhyaya MP. Clinically plausible hyperventilation does not exert adverse hemodynamic effects during CPR but markedly reduces end-tidal PCO 2 . Resuscitation. 2012;83:259-64.

29. Orlob S, Wittig J, Tenhunen J, Wnent J, Gräsner J-T, Prause G. Never quite there? - Hyperventilation in cardiopulmonary resuscitation. Resuscitation. 2021;165:138-9.

30. Soar J, Böttiger BW, Carli P, Couper K, Deakin CD, Djärv T, et al. European resuscitation council guidelines 2021: adult advanced life support. Resuscitation. 2021;161:115-51

31. Judge EP, Hughes JML, Egan JJ, Maguire M, Molloy EL, O’Dea S. Anatomy and bronchoscopy of the porcine lung. a model for translational respiratory medicine. Am J Resp Cell Mol. 2014:51:334-43.

32. Davis K, Johannigman JA, Johnson RC, Branson RD. Lung compliance following cardiac arrest. Acad Emerg Med. 1995;2:874-8.

33. Nolan JP, Monsieurs KG, Bossaert L, Böttiger BW, Greif R, Lott C, et al. European Resuscitation Council COVID-19 guidelines executive summary. Resuscitation. 2020;153:45-55.

34. Slutsky AS, Ranieri VM. Ventilator-Induced Lung Injury. New Engl J Med. 2013:369:2126-36.

35. Schuppen H van, Boomars R, Kooij FO, Tex P, den, Koster RW, Hollmann MW. Optimising airway management and ventilation during prehospital advanced life support in out-of-hospital cardiac arrest - a narrative review. Best Pract Res Clin Anaesthesiol. 2020;35:67-82.

36. Aggarwal P, Jamshed N, Sahu AK, Timilsina G, Mathew R. "Six-dial Strategy"Mechanical Ventilation during Cardiopulmonary Resuscitation. Indian J Critical Care Med. 2020;24:487-9.

37. Grieco DL, Brochard LJ, Drouet A, Telias I, Delisle S, Bronchti G, et al. Intrathoracic Airway Closure Impacts CO2 Signal and Delivered Ventilation during Cardiopulmonary Resuscitation. Am J Resp Crit Care. 2018;199:728-37.

38. Duchatelet C, Wolfskeil M, Vanwulpen M, Idrissi S-H. Effect of positive endexpiratory pressure during cardiopulmonary resuscitation on short-term survival. Resuscitation. 2019:142:e7-8.

39. Markstaller K, Karmrodt J, Doebrich M, Wolcke B, Gervais H, Weiler N, et al. Dynamic computed tomography: a novel technique to study lung aeration and atelectasis formation during experimental CPR. Resuscitation. 2002;53:307-13.

40. Leinonen M, Gravenstein N, Giordano C. Ventilation Is an Important Confounding Variable When End-Tidal Carbon Dioxide Is Used to Help Guide Cardiopulmonary Resuscitation. Anesth Analg. 2019;129:1436-8.

41. Khoury A, Luca AD, Sall FS, Pazart L, Capellier G. Ventilation feedback device for manual ventilation in simulated respiratory arrest: a crossover manikin study. Scand J Trauma Resusc Emerg Med. 2019;27:93.

42. Suarez-Sipmann F, Bohm SH, Tusman G. Volumetric capnography: the time has come. Curr Opin Crit Care. 2014;20:333-9.

43. Xu J, Yu X, Zhang L, Fu Y, Jin K, Yin L, et al. Modified volumetric capnography-derived parameter: a potentially stable indicator in monitoring cardiopulmonary resuscitation efficacy in a porcine model. Resuscitation. 2020;150:94-101.

\section{Publisher's Note}

Springer Nature remains neutral with regard to jurisdictional claims in published maps and institutional affiliations. 